\title{
Long-term variability of solar direct and global radiation derived from ISCCP data and comparison with reanalysis data
}

\author{
S. Lohmann ${ }^{\mathrm{a}, *}$, C. Schillings ${ }^{\mathrm{b}}$, B. Mayer ${ }^{\mathrm{a}}$, R. Meyer ${ }^{\mathrm{a}}$ \\ ${ }^{a}$ Institut für Physik der Atmosphäre, Deutsches Zentrum für Luft- und Raumfahrt, DLR Oberpfaffenhofen, D-82234 Wessling, Germany \\ b Institut für Technische Thermodynamik, Deutsches Zentrum für Luft- und Raumfahrt, DLR Stuttgart, Pfaffenwaldring \\ 38-40, D-70503 Stuttgart, Germany
}

Received 15 November 2004; received in revised form 7 March 2006; accepted 20 March 2006

Available online 2 May 2006

Communicated by: Associate Editor Klaus Vajen

\begin{abstract}
Annual variations of solar radiation at the Earth's surface may be strong and could seriously harm the return of investment for solar energy projects. This paper analyzes the long-term variability of broadband surface solar radiation based on 18 years of three-hourly satellite observations from the International Satellite Cloud Climatology Project (ISCCP). Direct normal irradiance (DNI) and global horizontal irradiance (GHI) at the surface are derived through radiative transfer calculations, using different physical input parameters describing the actual composition of the atmosphere. Validation of DNI is performed with two years of high resolution Meteosat-derived irradiance. Monthly averages show an average mean bias deviation of $-1.7 \%$. Results for DNI from the 18-year time series indicate strong and significant increases for several regions in the subtropics up to $+4 \mathrm{~W} / \mathrm{m}^{2}$ per year, with exception of Australia, where a small decrease in DNI of $-1 \mathrm{~W} / \mathrm{m}^{2}$ per year is observed. Inter-annual variability for DNI is very strong and sometimes exceeds $20 \%$. Comparisons of calculations with and without volcanic aerosol reveal a decrease of up to $16 \%$ in annual averages due to volcano eruptions. Changes in GHI are much smaller and less significant. Results show a maximum increase of $0.8 \mathrm{~W} / \mathrm{m}^{2}$ per year and an annual variability of less than $4 \%$. Volcano eruptions reduce annual averages of GHI by less than $2.2 \%$. The two reanalysis data sets investigated differ strongly from each other and are far off the validated results derived from satellite data. Trends are weaker and less significant or even of opposite sign.
\end{abstract}

(c) 2006 Elsevier Ltd. All rights reserved.

Keywords: Direct solar radiation; Radiative transfer; Global dimming

\footnotetext{
* Corresponding author. Tel.: +498153 282518; fax: +498153 281841.

E-mail addresses: Sina.Lohmann@dlr.de (S. Lohmann), Christoph.Schillings@dlr.de (C. Schillings), Bernhard. Mayer@dlr.de (B. Mayer), Richard.Meyer@dlr.de (R. Meyer).
}

\section{Introduction}

Rising interest in large scale solar energy applications requires reliable information on solar resources and their stability. Long-term data are needed for a valid selection of suitable sites. Knowledge of the variability of incoming radiation is 
required for estimates of worst case scenarios in solar power project development e.g. after volcano eruptions. Reliable long-term radiation measurements are rare, especially in areas that are interesting for solar energy applications.

Investigations based on surface measurements of global irradiance found a decrease until 1990 (Gilgen et al., 1998; Liepert, 2002). Latest findings of Wild et al. (2005) report an increase since 1990. The cause of this is assumed to be the changing aerosol content of the atmosphere. Very little is known about the long-term behaviour of direct radiation. An increasing direct/diffuse ratio was observed in Germany and the USA due to changing aerosol composition (Liepert and Tegen, 2002). After the eruption of Mount Pinatubo in 1991 a peak extinction of up to $27 \%$ on the direct beam was observed (Molineaux and Ineichen, 1996). Productivity of solar power plants after the eruption was 30\% lower than in years without volcanic pollution (Michalsky et al., 1994).

Reanalysis data sets assimilate observational data of the past in a temporally consistent way to produce a best estimate of the historical state of the atmosphere. Observational data from surface measurements, radiosondes, and recently also satellites are used to calculate the state of the atmosphere and its processes including radiative fluxes. The model output may be used to analyze variations of solar irradiance over time. However both reanalysis data sets seem to have problems reproducing all-sky irradiances (Allen et al., 2004; Yang et al., 1999).

To gain information about solar radiation over a long time period and at remote sites, satellite data are an ideal means since it covers the whole globe and has been recorded for many years now. Pinker et al. (2005) investigated the behaviour of global irradiance derived from ISCCP data and found a decrease until 1990 and an increase thereafter. No study has been performed on direct irradiance so far. Since direct irradiance is expected to react even stronger to changes in the atmosphere than global irradiance, results could be valuable not only for solar energy issues but also serve as a very sensitive indicator of climate variability.

\section{Method and input data}

Time series presented in this study are based on cloud data from the International Satellite Cloud Climatology Project (ISCCP). The ISCCP aims at providing a global climatology of clouds derived from operational weather satellite data and is compiled by NASA (Schiffer and Rossow, 1983). Below $55^{\circ}$ latitude the data of geostationary satellites (Meteosat, GOES, GMS, INSAT) are used, if available. At high latitudes and in case of failures of geostationary satellites, data from the polar orbiting NOAA-satellites are included. To reach good congruence all instruments are normalized to a common reference satellite. During this procedure all trends due to instrument drift and changing satellites are eliminated (Rossow et al., 1992; Brest et al., 1997). Several data sets have been produced by ISCCP. Most convenient for the purpose of this paper is the global ISCCP FD (flux D series) data set which is based on the D1 cloud data (Rossow and Schiffer, 1999) and currently covers the time from July 1983 to June 2001 with a spatial resolution of $280 \mathrm{~km}$ on an equal area grid and a temporal resolution of $3 \mathrm{~h}$. ISCCP cloud data include cloud top pressure, optical thickness, and top temperature (Rossow et al., 1996). Based on these properties 15 cloud types are differentiated and a cloud amount for each of them is given. Additionally TIROS Operational Vertical Sounder (TOVS) products, Total Ozone Mapping Spectrometer (TOMS) ozone products, a climatology of stratospheric and upper tropospheric water vapour from the Stratospheric Aerosol and Gas Experiment (SAGE) II and several other input data sets are used to produce longwave and shortwave radiative flux profiles of global irradiance (Zhang et al., 2004), but no direct irradiance is available in the ISCCP FD data set.

As input data to our radiative transfer calculations cloud data, ozone, precipitable water, and surface albedo are taken from the ISCCP FD input data set. An effective solar zenith angle for each three hour interval and the mean ground elevation for each grid box is also provided by ISCCP FD. Extraterrestrial solar radiation is corrected for the varying Sun-Earth-distance. Standard atmospheres (Anderson et al., 1986) for the different latitude regions and seasons are used as atmospheric background, with ozone column and precipitable water scaled to the values given by the ISCCP FD data set. Cloud top pressure is converted into a cloud top height. Cloud geometrical thickness is always set to $1000 \mathrm{~m}$ since it has negligible impact on surface irradiance values. For water clouds the transformation of liquid water content and effective droplet radius to optical properties is done with the parameterization of $\mathrm{Hu}$ and Stamnes (1993) with an effective droplet radius of $10 \mu \mathrm{m}$. For ice 


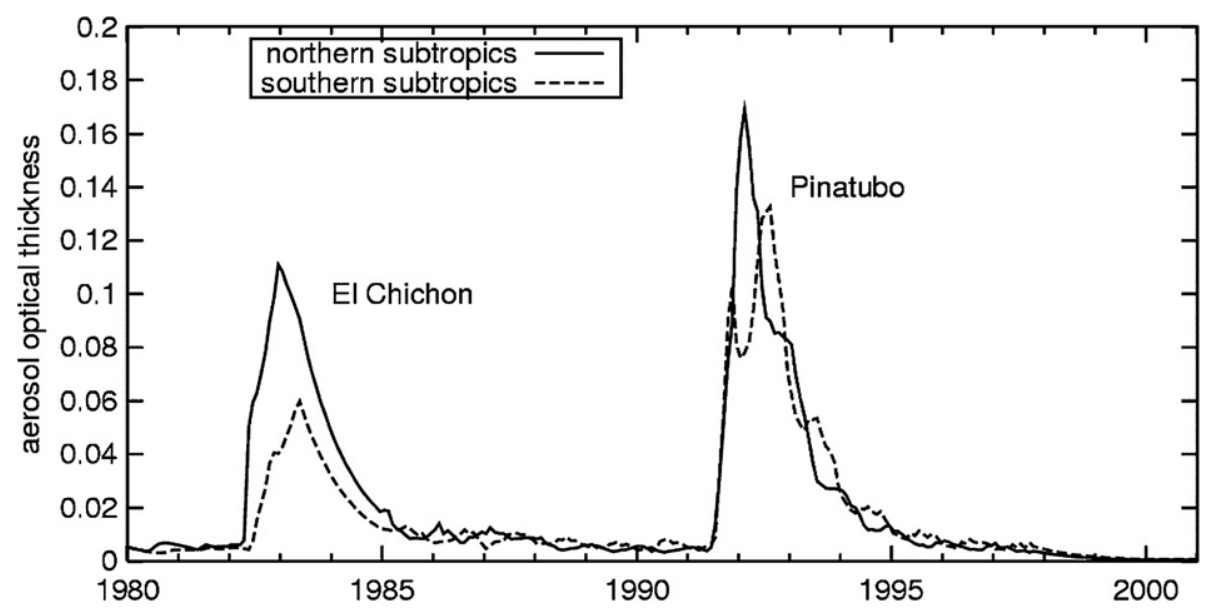

Fig. 1. Stratospheric aerosol optical thickness from (Sato et al., $1993+$ updates) for the northern and southern subtropics $\left(22.5^{\circ}-45^{\circ}\right.$ North/South). The eruptions of El Chichon and Pinatubo had more influence on the northern subtropics (solid line) than on the southern subtropics (dashed line).

clouds the parameterization of Yang and Key (Yang et al., 2000; Key et al., 2002) is used with an effective particle radius of $30 \mu \mathrm{m}$. This is consistent with the cloud optical properties retrieved in ISCCP (Rossow et al., 1996).

Special attention is given to aerosol. For tropospheric aerosol, 12 monthly climatological values are used, calculated by a combination of several transport models for four different aerosol species (Tegen et al., 1997). The spatial resolution of the data $\left(4^{\circ} \times 5^{\circ}\right)$ is remapped to fit the ISCCP grid. Thus, due to a lack of good data sets describing the actual aerosol content of the troposphere it is assumed that the concentration of tropospherical aerosol is constant throughout the years. Nevertheless the aerosol load of the atmosphere can show strong inter-annual fluctuations. These are strongest for the stratospheric aerosol content after a highreaching volcanic eruption. In case volcanic aerosol is ejected up to the stratosphere its contents typically have a decay time of one to two years (Robock, 2000). To account for this effect, monthly values of stratospheric optical thickness by Sato et al. (1993 + updates, Fig. 1) are added to the tropospheric background. The data span the time from 1850 to 1999 . For the period considered here optical thickness is derived from satellite data (Stratospheric Aerosol Measurement (SAM) II and SAGE II). The original $7.5^{\circ}$ latitude bands are interpolated to fit the ISCCP resolution and extended through June 2001 assuming an exponential decrease.

To derive direct irradiance from ISCCP and get independent results for global irradiance a proce- dure is developed which uses precise radiative transfer calculations. For this purpose the two-stream solver of Kylling et al. (1995) is used, which is part of the library for radiative transfer (libRadtran, Mayer and Kylling, 2005). The two-stream method solves the linear transport equation applicable to radiative transfer in a vertically inhomogeneous layered media. A 32-band correlated-k parameterization after Kato et al. (1999) is used for the calculation of spectrally integrated values over the solar spectral range (200-4300 nm). Radiative transfer calculations are carried out separately for clear sky and for each of the 15 ISCCP cloud types assuming homogeneous cloud layers. The results are summed, weighted with the cloud amount of each cloud type and the proportion of clear sky respectively to get 3-hourly irradiance values.

\section{Validation}

A validation of the newly developed libRadtranISCCP-method is performed by comparison with high precision Meteosat-derived DNI, according to Meyer et al. (2004), which is a slightly modified method of Schillings et al. (2004a). The Meteosatderived data have a spatial resolution of $5 \mathrm{~km}$ and has been validated against surface measurements from seven sites, showing a relative mean bias deviation (rMBD) of less than 2.5\% (Meyer et al., 2004). Irradiance values from this half-hourly Meteosat data with $5 \mathrm{~km}$ nominal resolution are calculated for the area of $280 \mathrm{~km} \times 280 \mathrm{~km}$, matching the position of one ISCCP box. Results are then averaged 
temporally and spatially to match the ISCCP resolution. Using this method for validation avoids comparison of satellite data with low spatial resolution $(280 \mathrm{~km})$ to single spot ground measurements. Therefore errors due to differing scales can be minimized.

The period for the comparison covers two years (1999, 2000). For 10 ISCCP-boxes monthly averages are included in the validation procedure, their ISCCP box numbers and geographical locations are listed in Table 1. Fig. 2 shows a plot of both time

Table 1

Geographical location of ISCCP boxes with centre coordinates and land coverage

\begin{tabular}{llrrc}
\hline $\begin{array}{l}\text { ISCCP } \\
\text { box no. }\end{array}$ & Region & Latitude & Longitude & $\begin{array}{l}\text { Land } \\
\text { coverage } \\
(\%)\end{array}$ \\
\hline $1657^{\mathrm{a}}$ & South Africa & $-28.75^{\circ}$ & $21.43^{\circ}$ & 100 \\
$1759^{\mathrm{b}}$ & Southern Atlantic & $-28.75^{\circ}$ & $47.14^{\circ}$ & 1 \\
& and Brazil & & & \\
$1954^{\mathrm{a}}$ & Australia & $-23.75^{\circ}$ & $135.00^{\circ}$ & 100 \\
$4563^{\mathrm{b}}$ & Algeria & $23.75^{\circ}$ & $6.82^{\circ}$ & 100 \\
$4578^{\mathrm{b}}$ & Saudi Arabia & $23.75^{\circ}$ & $47.73^{\circ}$ & 100 \\
$4834^{\mathrm{a}, \mathrm{b}}$ & Saudi Arabia, & $28.75^{\circ}$ & $35.71^{\circ}$ & 94 \\
& Jordan, Israel & & & \\
& and Egypt & & & \\
$4959^{\mathrm{b}}$ & Israel and Egypt & $31.25^{\circ}$ & $33.66^{\circ}$ & 61 \\
$4960^{\mathrm{b}}$ & Jordan, Israel & $31.25^{\circ}$ & $36.59^{\circ}$ & 100 \\
& and Saudi Arabia & & & \\
$5417^{\mathrm{b}}$ & Spain & $38.75^{\circ}$ & $4.82^{\circ}$ & 100 \\
$5528^{\mathrm{b}}$ & France and & $43.75^{\circ}$ & $5.19^{\circ}$ & 69 \\
& Mediterranean & & & \\
$5632^{\mathrm{b}}$ & France and & $46.25^{\circ}$ & $5.40^{\circ}$ & 100 \\
& Switzerland & & & \\
$5829^{\mathrm{b}}$ & Germany and & $51.25^{\circ}$ & $14.00^{\circ}$ & 100 \\
& Poland & & & \\
\hline
\end{tabular}

${ }^{a}$ Results are shown in example plots (Figs. 3, 5 and 6).

${ }^{b}$ Boxes used for validation. series for an ISCCP-box covering parts of Saudi Arabia, Jordan, Israel and Egypt. The libRadtranISCCP-procedure describes well the annual cycle with a correlation coefficient $r$ of 0.94 (average over 10 boxes is 0.95 , see Table 2). The rMBD varies between $-10 \%$ and $+5 \%$ with an average $-1.7 \%$. DNI calculated by the libRadtran-ISCCP method is mostly smaller than the Meteosat-derived results, only two ISCCP boxes show higher values. These boxes both cover more then $30 \%$ of ocean. The Meteosat-derived DNI has yet to be validated for regions over sea, therefore results might be less reliable.

The root mean square deviation (RMSD) averaged over 10 boxes is $10.5 \%$ for monthly values. We don't have enough data to calculate an RMSD for annual averages. Assuming a linear dependence between RMSD and time resolution (Schillings et al., 2004b), the deviation for annual averages

Table 2

Deviations of monthly means of DNI calculated with libRadtran from Meteosat-derived irradiance that was averaged temporally and spatially to match ISCCP resolution

\begin{tabular}{lcllr}
\hline $\begin{array}{l}\text { ISCCP } \\
\text { box no. }\end{array}$ & rMBD $(\%)$ & $\begin{array}{l}\text { Correlation } \\
\text { coefficient } r\end{array}$ & $\begin{array}{l}\text { RMSD } \\
\left(\mathrm{W} / \mathrm{m}^{2}\right)\end{array}$ & $\begin{array}{l}\text { RMSD } \\
(\%)\end{array}$ \\
\hline 1759 & 3.2 & 0.98 & 10.5 & 9.5 \\
4563 & -10.4 & 0.96 & 32.0 & 11.3 \\
4578 & -3.1 & 0.76 & 31.1 & 13.3 \\
4834 & -2.0 & 0.94 & 18.6 & 7.6 \\
4959 & -7.3 & 0.97 & 24.7 & 9.8 \\
4960 & -2.4 & 0.94 & 24.9 & 10.1 \\
5417 & -1.5 & 0.99 & 14.5 & 6.4 \\
5528 & 5.0 & 0.98 & 13.8 & 7.7 \\
5632 & -1.0 & 0.98 & 10.4 & 10.3 \\
5829 & 0.5 & 0.99 & 18.7 & 18.7 \\
All boxes & -1.7 & 0.95 & 19.3 & 10.5 \\
\hline
\end{tabular}

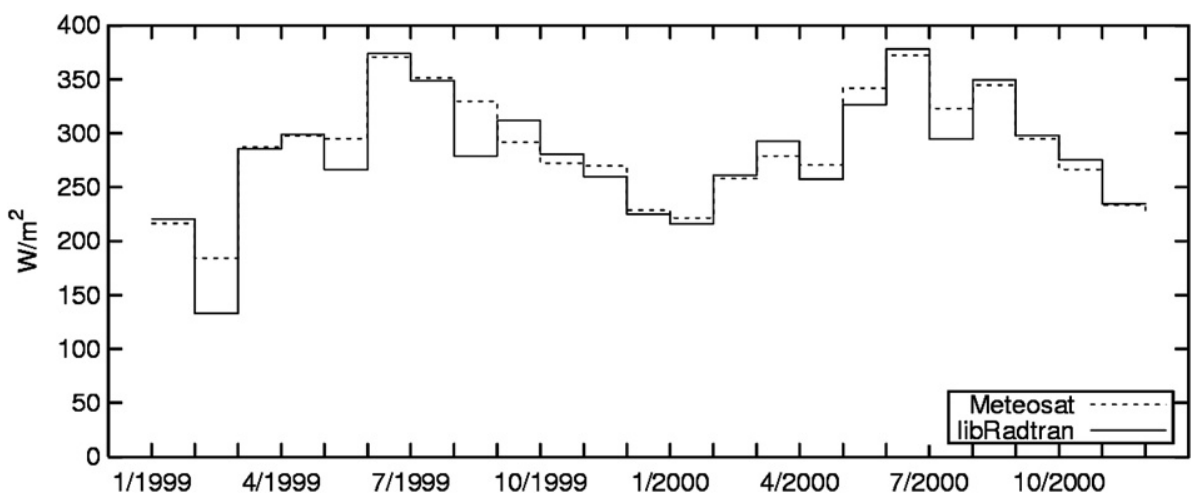

Fig. 2. Monthly averages of DNI derived from high-resolution Meteosat data and by libRadtran from ISCCP FD input data for ISCCP box 4834 (Near East). 
can be derived from the monthly data, resulting in an estimated RMSD of $4.2 \%$.

\section{Results}

Annual averages of DNI for three ISCCP boxes are shown in Fig. 3 (dark bars). A linear regression (solid line) reveals a strong increase of DNI during the observation period for the ISCCP boxes in the Near East (box $4834,+3.9 \mathrm{~W} / \mathrm{m}^{2}$ per year) and South Africa (box 1657, $+2.4 \mathrm{~W} / \mathrm{m}^{2}$ per year), whereas the Australian box shows slightly decreasing values (box $1954,-0.9 \mathrm{~W} / \mathrm{m}^{2}$ per year). The significance of these trends is tested using a students $t$ test (Press et al., 1992). Significance levels as well as 18-year means and linear regressions for the 12 boxes used in this study are given in Table 3.

The eruption of El Chichon at the beginning of the analysis period (Fig. 1) may have severely influenced the observed trends towards an increase. Therefore the calculations are repeated excluding volcanic aerosols. The eruption of El Chichon (April 1982)
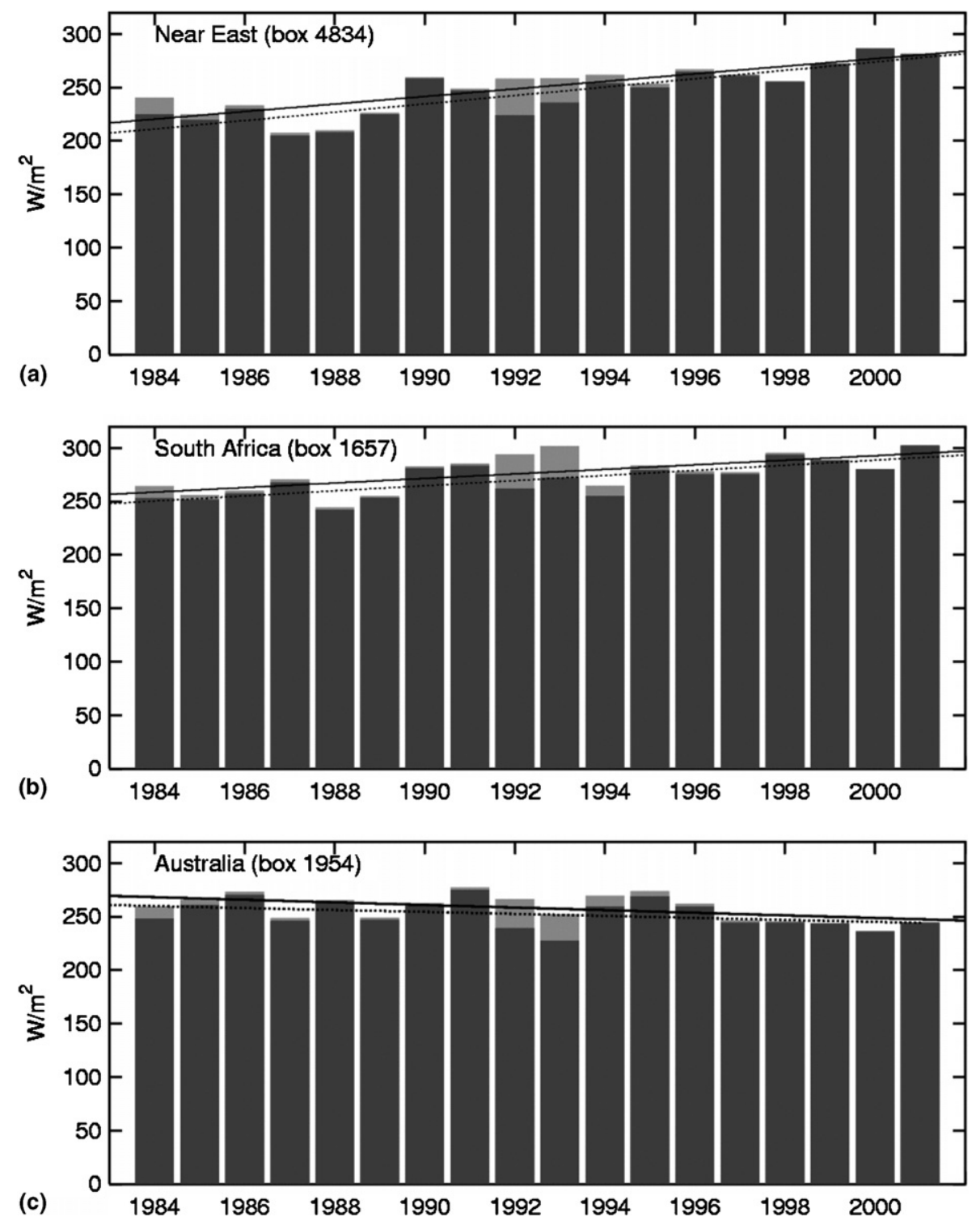

Fig. 3. Annual averages of DNI for three ISCCP-boxes. Results obtained including volcanic aerosol (dark bars, solid regression) and neglecting volcanic aerosol (pale extensions, dotted regression) show strong positive trends for box 4834 (Near East, a) and 1657 (South Africa, b). Results for an Australian box $(1954, \mathrm{c})$ indicate a negative trend. 
Table 3

Long-term averages and trends of DNI and GHI derived from ISCCP cloud data with libRadtran. Results for time series in Fig. 3 are bold

\begin{tabular}{|c|c|c|c|c|c|c|c|c|}
\hline \multirow{2}{*}{$\begin{array}{l}\text { DNI } \\
\text { ISCCP } \\
\text { box no. }\end{array}$} & \multicolumn{4}{|c|}{ DNI with stratospheric aerosol } & \multicolumn{4}{|c|}{ DNI without stratospheric aerosol } \\
\hline & $\begin{array}{l}\text { 18-year } \\
\text { mean } \\
\left(\mathrm{W} / \mathrm{m}^{2}\right)\end{array}$ & $\begin{array}{l}\text { Std. dev } \\
\left(\mathrm{W} / \mathrm{m}^{2}\right)\end{array}$ & $\begin{array}{l}\text { Slope of linear } \\
\text { regression } \\
\left(\mathrm{W} / \mathrm{m}^{2} / \mathrm{yr}\right)\end{array}$ & $\begin{array}{l}\text { Significance } \\
(\%)\end{array}$ & $\begin{array}{l}18 \text {-year } \\
\text { mean }\left(\mathrm{W} / \mathrm{m}^{2}\right)\end{array}$ & $\begin{array}{l}\text { Std. dev } \\
\left(\mathrm{W} / \mathrm{m}^{2}\right)\end{array}$ & $\begin{array}{l}\text { Slope of } \\
\text { linear regression } \\
\left(\mathrm{W} / \mathrm{m}^{2} / \mathrm{yr}\right)\end{array}$ & $\begin{array}{l}\text { Significance } \\
(\%)\end{array}$ \\
\hline 1657 & 270.7 & 16.5 & +2.4 & 99 & 276.9 & 16.8 & +2.1 & 99 \\
\hline 1759 & 141.4 & 11.9 & +1.0 & 95 & 144.7 & 10.8 & +0.9 & 95 \\
\hline 1954 & 252.1 & 13.0 & -0.9 & 90 & 257.9 & 12.2 & -1.2 & 95 \\
\hline 4563 & 244.4 & 15.6 & +2.3 & 99 & 250.5 & 13.3 & +1.7 & 99 \\
\hline 4578 & 201.9 & 27.6 & +3.0 & 99 & 206.2 & 23.8 & +2.6 & 99 \\
\hline 4834 & 244.4 & 24.2 & +3.9 & 99 & 250.4 & 22.5 & +3.5 & 99 \\
\hline 4959 & 213.3 & 13.8 & +1.6 & 99 & 218.5 & 11.2 & +1.2 & 99 \\
\hline 4960 & 210.1 & 22.2 & +3.5 & 99 & 215.2 & 20.0 & +3.2 & 99 \\
\hline 5417 & 209.7 & 20.9 & +2.2 & 99 & 217.6 & 17.7 & +1.6 & 95 \\
\hline 5528 & 166.8 & 18.4 & +2.4 & 99 & 172.9 & 15.4 & +2.0 & 99 \\
\hline 5632 & 116.7 & 13.6 & +0.4 & $<80$ & 122.1 & 13.2 & -0.1 & $<80$ \\
\hline 5829 & 75.6 & 8.6 & +0.2 & $<80$ & 79.1 & 10.4 & -0.1 & $<80$ \\
\hline GHI & \multicolumn{4}{|c|}{ GHI with stratospheric aerosol } & \multicolumn{4}{|c|}{ GHI without stratospheric aerosol } \\
\hline 1657 & 254.8 & 3.5 & +0.3 & 90 & 255.6 & 3.6 & +0.2 & 90 \\
\hline 1759 & 194.0 & 5.4 & -0.1 & $<80$ & 194.8 & 5.4 & -0.1 & $<80$ \\
\hline 1954 & 252.6 & 4.6 & -0.4 & 95 & 253.4 & 4.5 & -0.4 & 95 \\
\hline 4563 & 264.8 & 3.6 & +0.3 & 95 & 265.7 & 3.7 & +0.2 & 90 \\
\hline 4578 & 263.2 & 6.7 & +0.3 & $<80$ & 264.0 & 6.2 & +0.3 & $<80$ \\
\hline 4834 & 256.9 & 4.8 & +0.7 & 99 & 257.9 & 4.5 & +0.6 & 99 \\
\hline 4959 & 236.3 & 3.8 & +0.4 & 95 & 237.2 & 3.5 & +0.3 & 95 \\
\hline 4960 & 242.6 & 5.4 & +0.8 & 99 & 243.5 & 5.0 & +0.7 & 99 \\
\hline 5417 & 204.3 & 6.3 & +0.5 & 95 & 205.4 & 6.0 & +0.2 & 90 \\
\hline 5528 & 171.9 & 5.5 & +0.6 & 99 & 172.9 & 5.1 & +0.6 & 99 \\
\hline 5632 & 147.8 & 4.8 & -0.2 & $<80$ & 149.0 & 5.0 & -0.3 & 90 \\
\hline 5829 & 120.9 & 5.3 & -0.1 & $<80$ & 121.9 & 5.9 & -0.2 & $<80$ \\
\hline
\end{tabular}

and also Mt. Pinatubo (June 1991) causes a maximum reduction of up to $16 \%$ for annual averages and can be recognized for at least three years (grey extensions in Fig. 3). The 18-year mean is increased by up to $4.6 \%$. Trends are shifted by $-0.4 \mathrm{~W} / \mathrm{m}^{2}$ per year on average (Table 3 and dotted lines in Fig. 3). For two boxes, this results in a change from a weak positive to a weak negative trend. Neither of these trends is statistically significant.

Results for GHI are summarized in Table 3 (bottom). Time series mostly show trends of the same sign as DNI but smaller magnitude, for three boxes trends are of opposite sign. Again these trends are not significant. Values for single years increase by

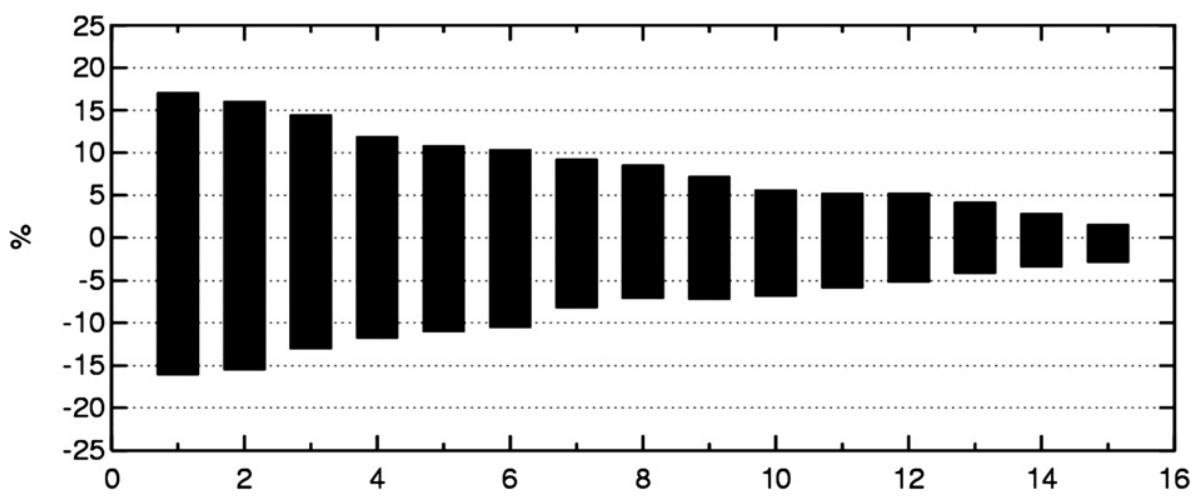

Fig. 4. Minimum and maximum deviation from the 18-year mean, when averaging over limited time spans from 1 to 15 years. Data refer to box 4834 (Near East). 
up to $2.2 \%$ when calculated without volcanic aerosol, the 18 -year average by a maximum of $0.8 \%$.

Time series in Fig. 3 also point out that even without influence of volcanic aerosol the interannual variations of direct irradiance are strong. If short time series are used to derive long-term averages, errors in the estimates can be large. Fig. 4 depicts the maximum deviation of averages over shorter time periods from the 18-year average for the box number 4834 (Saudi Arabia/Jordan/Israel/ Egypt). It becomes obvious that it is hardly possible to analyze the suitability of a site for solar systems with a short time-period of data. Taking results from one year of measurements could be more than $15 \%$ above or below the long-term average. Averaging five years still could lead to deviations larger than $10 \%$. Thus, at least 10 years of data should be taken into account to gather reliable information on solar resources.

\section{Comparison with other data sets}

To further validate our results we compare our global irradiance data with several other data sets.
The European Centre for Medium-Range Weather Forecasts (ECMWF) ERA-40 (Simmons and Gibson, 2000) data set spans 45 years from 1957 to 2002. In this paper the output with six-hourly temporal and $2.5^{\circ}$ spatial resolution is used. Concerning irradiance data the ERA-40 reanalysis provides sums of global, but no information about direct irradiance. The National Centers for Environmental Prediction/National Center for Atmospheric Research (NCEP/NCAR) Reanalysis (Kalnay et al., 1996) cover the time from 1948 to present with a temporal resolution of six hours and a T62 horizontal resolution $(\sim 210 \mathrm{~km})$. Surface radiation data include global and direct radiation. The latter spans only the visible spectral range. Additionally global irradiance provided by the ISCCP FD data set is also included in the comparison. Naturally it has the same temporal and spatial resolution as the results derived with libRadtran.

Both the ERA-40 and the NCEP/NCAR grids coincide neither with each other nor with the ISCCP grid. Therefore results for nine ISCCP grid boxes are spatially averaged, centered around the boxes presented as examples for DNI time series in Section

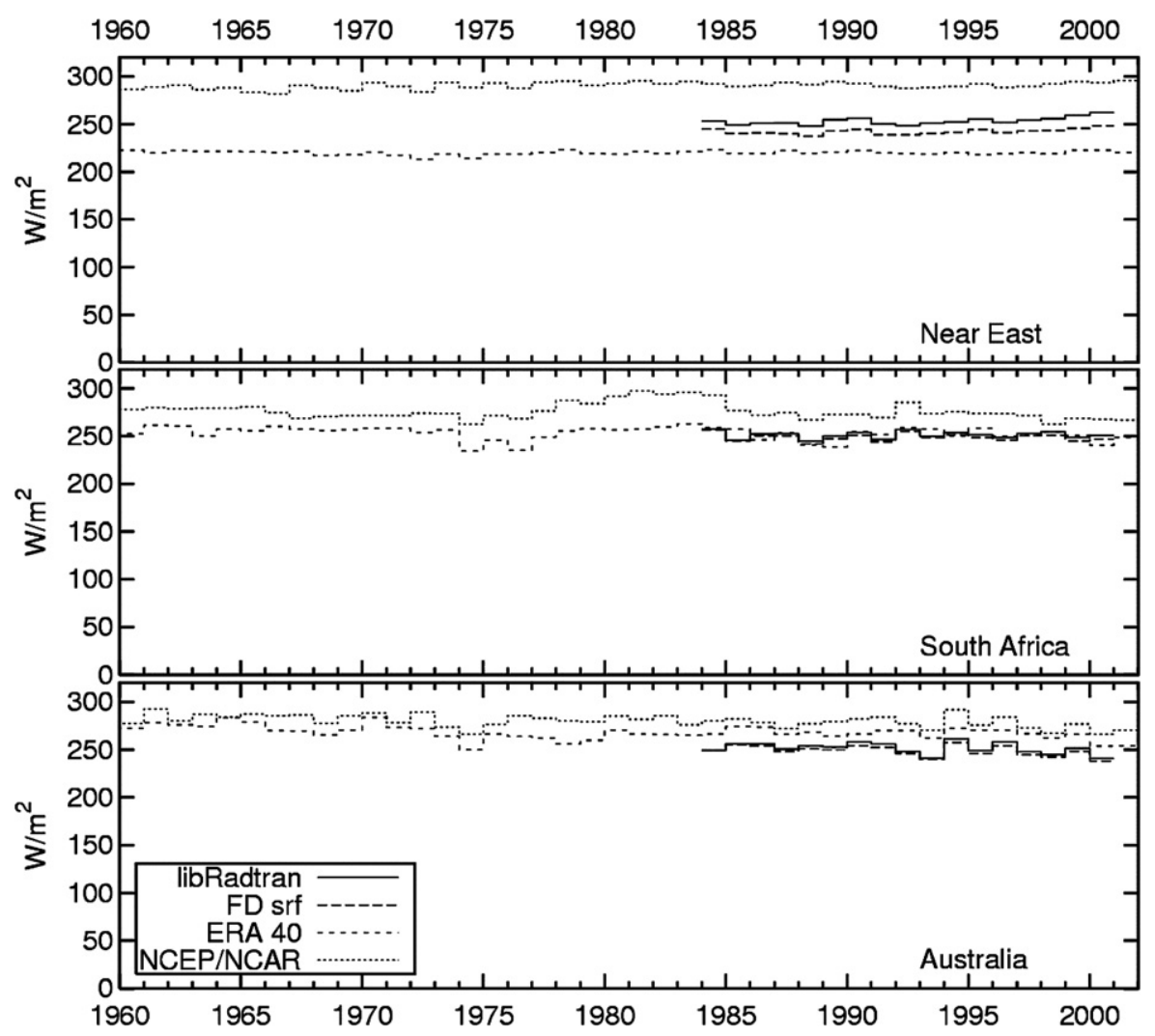

Fig. 5. Annual averages of GHI for the Near East (top), South Africa (middle) and Australia (bottom). 
4. A variable number of reanalysis grid boxes is chosen such that the area of the nine ISCCP boxes is best covered. Annual averages for all four data sets are shown in Fig. 5.

Annual averages of GHI calculated with libRadtran and from ISCCP surface flux data (FD srf) show good agreement for two out of three regions (Fig. 5, Table 4). The time series for the Near East shows a slight offset between the two curves of $4.4 \%$ on average, but both data sets include a significant positive trend and demonstrate the same temporal characteristics.

GHI from ERA-40 reanalysis is lower than the ISCCP derived values for the Near East region but shows generally good agreement for the South African region. For Australia the ERA-40 curve lies slightly above the ISCCP derived curve. Trends for South Africa and Australia are significant. A closer investigation of the 17 years overlapping with ISCCP data shows a significant trend for Australia only.
GHI from the NCEP/NCAR reanalysis is higher than all other data sets for all regions considered here. The 56-year curve shows a significant positive trend for the Near East region and a significant negative trend for Australia. Considering only the 17 years overlapping with ISCCP, trends for South Africa and Australia become significant (Table 4).

To evaluate the strong trends in DNI annual averages of direct radiation from the NCEP/NCAR reanalysis are analyzed. This reanalysis irradiation data cover the visible range from $500 \mathrm{~nm}$ to $700 \mathrm{~nm}$ (NCAR, 2004). LibRadtran-ISCCP-derived results are recalculated to match this spectral range. NCEP results are much higher than libRadtranISCCP values (Fig. 6 and Table 5). Major reason for the strong overestimation might be that the NCEP/NCAR derived visible spectrum range for DNI is actually wider than indicated at NCAR (2004). The direct irradiance in the NCEP data are rarely used and not well documented. Temporal characteristics of the two time series show very poor

Table 4

Long-term averages and trends of GHI from ISCCP-based and reanalysis data

\begin{tabular}{|c|c|c|c|c|}
\hline & $\begin{array}{l}\text { Location of } \\
\text { investigated area }\end{array}$ & $\begin{array}{l}\text { Average } \\
1984-2000 \\
\left(\mathrm{~W} / \mathrm{m}^{2}\right)\end{array}$ & $\begin{array}{l}\text { Slope }\left(\mathrm{W} / \mathrm{m}^{2} / \mathrm{yr}\right) \\
\text { of linear regression }\end{array}$ & Significance $(\%)$ \\
\hline \multicolumn{5}{|l|}{ Global horizontal irradiance } \\
\hline \multirow[t]{3}{*}{ ISCCP with libRadtran } & South Africa & 251.2 & +0.0 & $<80$ \\
\hline & Australia & 251.4 & -0.5 & 90 \\
\hline & Near East & 253.3 & +0.5 & 95 \\
\hline \multirow[t]{3}{*}{ ISCCP FD surface flux data } & South Africa & 248.8 & -0.1 & $<80$ \\
\hline & Australia & 248.9 & -0.6 & 95 \\
\hline & Near East & 242.2 & +0.3 & 90 \\
\hline \multirow[t]{3}{*}{ ERA-40 } & South Africa & 251.3 & -0.2 & $<80$ \\
\hline & Australia & 267.2 & -0.5 & 95 \\
\hline & Near East & 220.4 & -0.0 & $<80$ \\
\hline \multirow[t]{3}{*}{ NCEP/NCAR reanalysis } & South Africa & 273.7 & -0.7 & 95 \\
\hline & Australia & 277.5 & -0.5 & 90 \\
\hline & Near East & 291.3 & +0.0 & $<80$ \\
\hline \multirow[t]{5}{*}{ ERA-40 } & Location of & Average & Slope $\left(\mathrm{W} / \mathrm{m}^{2} / \mathrm{yr}\right)$ & Significance $(\%)$ \\
\hline & investigated area & $\begin{array}{l}1957-2002 \\
\left(\mathrm{~W} / \mathrm{m}^{2}\right)\end{array}$ & of linear regression & \\
\hline & South Africa & 253.0 & -0.2 & 95 \\
\hline & Australia & 268.3 & -0.2 & 99 \\
\hline & Near East & 220.1 & +0.0 & $<80$ \\
\hline \multirow[t]{5}{*}{ NCEP/NCAR reanalysis } & Location of & Average & Slope $\left(\mathrm{W} / \mathrm{m}^{2} / \mathrm{yr}\right)$ & Significance $(\%)$ \\
\hline & investigated area & $\begin{array}{l}1948-2004 \\
\left(\mathrm{~W} / \mathrm{m}^{2}\right)\end{array}$ & of linear regression & \\
\hline & South Africa & 274.2 & +0.1 & $<80$ \\
\hline & Australia & 281.8 & -0.2 & 99 \\
\hline & Near East & 289.5 & +0.2 & 99 \\
\hline
\end{tabular}




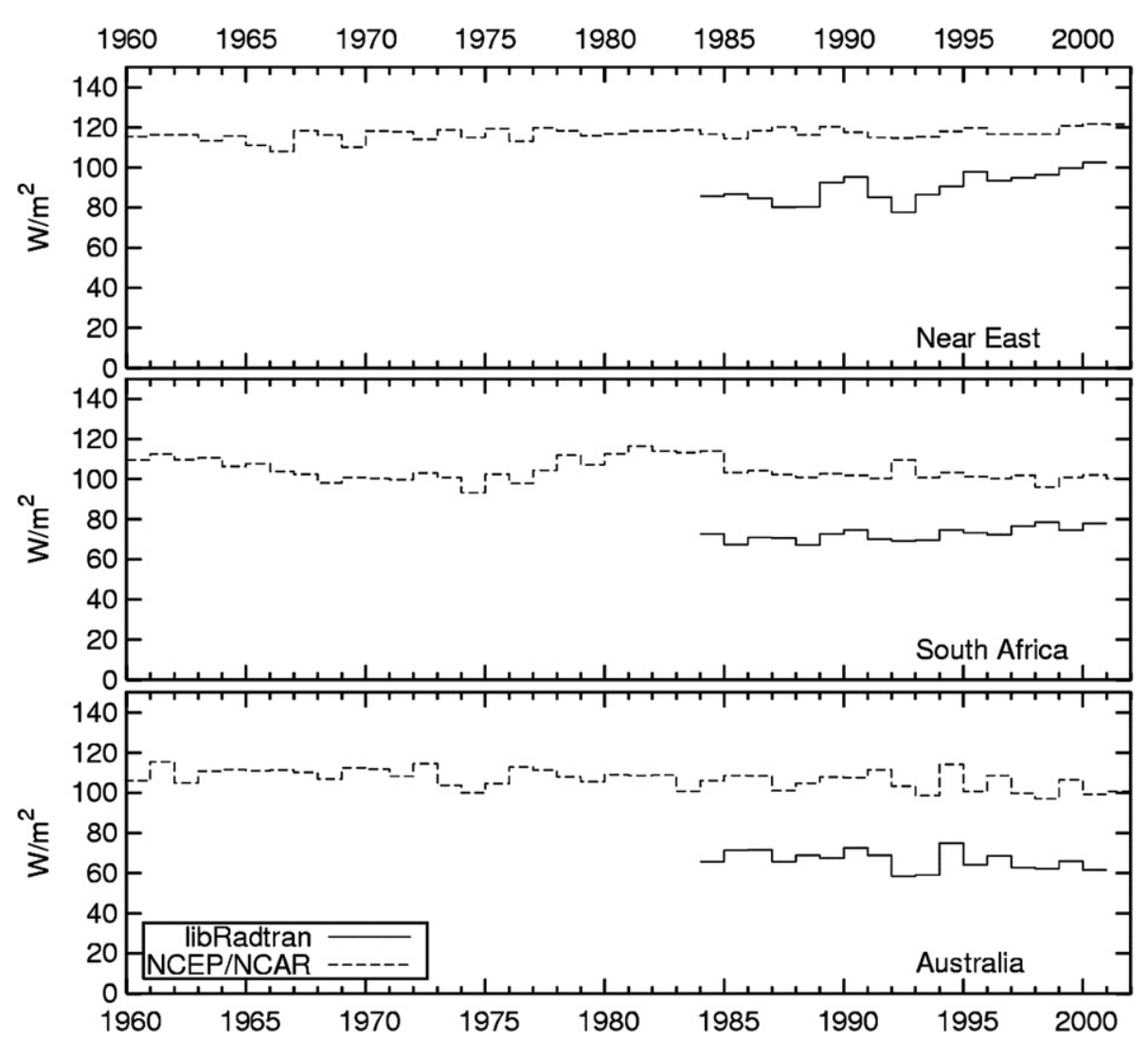

Fig. 6. Annual averages of DNI calculated with libRadtran (cont. line) including stratospheric aerosol and NCEP/NCAR reanalysis (dashed) for areas in the Near East (top), South Africa (middle) and Australia (bottom) (values refer only to spectral range from $500 \mathrm{~nm}$ to $700 \mathrm{~nm})$.

Table 5

Long-term averages and trends of DNI (500-700 nm) for the ISCCP-libRadtran derived results and NCEP/NCAR reanalysis data

\begin{tabular}{|c|c|c|c|c|}
\hline & $\begin{array}{l}\text { Location of } \\
\text { investigated area }\end{array}$ & $\begin{array}{l}\text { Average } \\
1984-2000\left(\mathrm{~W} / \mathrm{m}^{2}\right)\end{array}$ & $\begin{array}{l}\text { Slope }\left(\mathrm{W} / \mathrm{m}^{2} / \mathrm{yr}\right) \\
\text { of linear regression }\end{array}$ & Significance $(\%)$ \\
\hline \multicolumn{5}{|c|}{ Direct normal irradiance $(500-700 \mathrm{~nm})$} \\
\hline \multirow[t]{3}{*}{ ISCCP with libRadtran } & South Africa & 72.5 & +0.5 & 95 \\
\hline & Australia & 66.4 & -0.4 & 90 \\
\hline & Near East & 62.8 & +0.7 & 95 \\
\hline \multirow[t]{4}{*}{ NCEP/NCAR Reanalysis } & South Africa & 102.7 & -0.4 & 95 \\
\hline & Australia & 104.9 & -0.4 & 90 \\
\hline & Near East & 117.6 & +0.1 & $<80$ \\
\hline & $\begin{array}{l}\text { Location of } \\
\text { investigated area }\end{array}$ & $\begin{array}{l}\text { Average } \\
1948-2004\left(\mathrm{~W} / \mathrm{m}^{2}\right)\end{array}$ & $\begin{array}{l}\text { Slope }\left(\mathrm{W} / \mathrm{m}^{2} / \mathrm{yr}\right) \\
\text { of linear regression }\end{array}$ & Significance $(\%)$ \\
\hline \multirow[t]{3}{*}{ NCEP/NCAR Reanalysis } & South Africa & 103.0 & +0.0 & $<80$ \\
\hline & Australia & 108.6 & -0.2 & 99 \\
\hline & Near East & 115.8 & +0.1 & 99 \\
\hline
\end{tabular}

agreement for South Africa and the Near East, but at least a similar pattern for the Australian region. An investigation of the 17 years overlapping with ISCCP data reveals a weak positive trend for the
Near East region in the NCEP data set. The two locations on the southern hemisphere show weak negative trends in the NCEP data within the 17 year time span, that are significant. Considering the com- 
plete 56 years covered by the reanalysis data a significant slightly positive trend is identified for the Near East region and a significant negative trend for Australia.

The areas of the compared regions do not match entirely, since the reanalysis data sets have differing spatial resolutions. Therefore some deviations were expected. But the magnitude of the differences is surprisingly high. However, for the NCEP/NCAR reanalysis earlier studies reported a persistent overestimate of the reflected solar radiation, possibly related to shortcomings in the cloud/moisture parameterization in the NCEP assimilation system (Yang et al., 1999). For the ERA-40 large systematic biases in the total-sky radiation budget are reported by Allen et al. (2004), probably related to inaccurate radiative properties of clouds in the model.

\section{Summary and conclusions}

The radiative transfer calculations presented in this paper are based as far as possible on observational data of the atmosphere. Special attention was given to DNI, as no other data set is available providing direct irradiance over a long time period. Clouds are the most important part of the atmosphere concerning radiation. Therefore cloud data from the ISCCP FD input data set were used to provide a consistent global data set over 18 years. Since global long-term data are not available for tropospheric aerosol properties, a climatological annual cycle is included that does not vary from year to year. Thus, the true variability of the irradiance might be even stronger than calculated here. Furthermore, no information about the vertical distribution of atmospheric constituents especially tropospheric aerosol was included. This, however, affects only the diffuse irradiance, while for direct irradiance only the integrated optical thickness of the atmosphere is relevant.

An 18-year time series of DNI and GHI has been calculated with libRadtran. Validation with high resolution Meteosat-derived direct radiation indicates that the method is reliable and well reproducing monthly averages with an average rMBD of $-1.7 \%$. Strong and significant trends were found for several regions in the subtropics in the time series of DNI. The largest increase is occurring in the Near East region $\left(+3.9 \mathrm{~W} / \mathrm{m}^{2}\right.$ per year). So far a negative trend could be identified only for ISCCP boxes in Australia $\left(-1 \mathrm{~W} / \mathrm{m}^{2}\right.$ per year). Trends in
GHI are correlated, but up to a factor 10 weaker. However, these changes are still mostly significant. Only a small part of the discovered trends can be explained by volcanic aerosol (the eruption of $\mathrm{El}$ Chichon decreases irradiance values at the beginning of the studied time period), as calculations without volcanic aerosol proved. A possible explanation for the observed temporal characteristics are changes in cloud cover and their optical properties. Calculations have to be expanded to more regions of the globe to get a better overview of the processes in the Earth's atmosphere.

Comparisons of the libRadtran-ISCCP-results including and excluding stratospheric aerosol reveal a strong influence of volcanic eruptions on direct irradiance with a maximum attenuation of $16 \%$ for annual averages of DNI. Annual variability of DNI is large, not only for reasons of volcano eruptions, but also due to strong variability of cloud amount. Results indicate that only with a time series of at least 10 years a reliable assessment of direct solar radiation resource can be made which differs less than 5\% from the long-term average. Again the effect is much weaker for GHI, with a maximum attenuation of $2 \%$ for annual averages. This can be explained by the fact that changes in cloud amount or aerosol load directly diminish or enhance direct irradiance, whereas for global irradiance a decrease of the direct fraction is mostly compensated by an increase of the diffuse fraction and vice versa.

Comparison of the results with GHI provided by the ISCCP FD srf data set shows very good agreement of the temporal characteristics. For two regions ISCCP FD srf underestimates GHI by $1 \%$. The Near East region revealed an average deviation of $4.4 \%$ between the two curves. Data refer to a spatial average of nine ISCCP boxes, therefore the effect is not spatially confined. One possible explanation could be the different aerosol data sets used for the radiative transfer calculations.

Irradiance data provided by reanalysis projects fit only roughly the characteristics of long-term variability of solar radiation. DNI for the visible spectrum taken from the NCEP/NCAR reanalysis showed an average overestimation of $64 \%$. GHI from the ERA-40 data set underestimates yearly values on average by $6 \%$, the NCEP/NCAR reanalysis data are on average $11 \%$ too high. Inter-annual variability also shows poor agreement. The main source of error is assumed to be the cloud parameterization in current reanalysis models. Therefore for a reliable assessment of the solar resource 
quality long-term satellite-based irradiance data should be used.

\section{Acknowledgements}

Acknowledgements to the Helmholtz-Gemeinschaft for partly funding this research within the Virtual Institute for Energy Meteorology and to BMU (German Federal Ministry for the Environment, Nature Conservation and Nuclear Safety) for contributions within the projects PARASOL/ SKAL ET (Hochskalierung der Eurotrough Technologie), AndaF\& E (Erforschung und Entwicklung solarthermischer Kraftwerke) and SOLEMI-VALISAT. Many thanks to NASA Goddard for sharing the ISCCP data set and also to NCEP/NCAR and ECMWF for providing reanalysis data.

\section{References}

Allen, R.P., Ringer, M.A., Pamment, J.A., Slingo, A., 2004. Simulation of the Earth's radiation budget by the European Centre for Medium-Range Weather Forecasts 40-year reanalysis (ERA40). J. Geophys. Res., 109. doi:10.1029/ 2004JD004816, D18107.

Anderson, G.P., Clough, S.A., Kneizys, F.X., Chetwynd, J.H., Shettle, E.P., 1986. AFGL Atmospheric Constituent Profiles (0-120 km). AFGL-TR-86-0110, AFGL (OPI), Hanscom AFB, MA 01736.

Brest, C.L., Rossow, W.B., Roiter, M.D., 1997. Update of radiance calibrations for ISCCP. J. Atmos. Oceanic Technol. 14, 1091-1109.

Gilgen, H., Wild, M., Ohmura, A., 1998. Means and trends of shortwave irradiance at the surface estimated from Global Energy Balance Archive Data. J. Clim. 11, 2042-2061.

Hu, Y.X., Stamnes, K., 1993. An accurate parameterization of the radiative properties of water clouds suitable for use in climate models. J. Climate 6, 728-742.

Kato, S., Ackermann, T.P., Mather, J.H., Clothiaux, E.E., 1999. The $k$-distribution method and correlated-k approximation for a shortwave radiative transfer model. J. Quant. Spetrosc. Radiat. Transfer 62, 109-121.

Key, J., Yang, P., Baum, B., Nasiri, S., 2002. Parameterization of shortwave ice cloud optical properties for various particle habits. J. Geophys. Res., 107. doi:10.1029/2001JD000742, D3.

Kylling, A., Stamnes, K., Tsay, S.-C., 1995. A reliable and efficient two-stream algorithm for spherical radiative transfer: documentation of accuracy in realistic layered media. J. Atmos. Chem. 21, 115-150.

Liepert, B.G., 2002. Observed reductions of surface solar radiation at sites in the United States and worldwide from 1961 to 1990. Geophys. Res. Lett. 29 (10), 61.1-61.4.

Liepert, B.G., Tegen, I., 2002. Multidecadal solar radiation trends in the United States and Germany and direct tropospheric aerosol forcing. J. Geophys. Res., 107. doi:10.1029/ 2001JD000760, D12.
Mayer, B., Kylling, A., 2005. The libRadtran software package for radiative transfer calculations: description and examples of use. APCD 5, 1319-1381.

Meyer, R., Hoyer, C., Diedrich, E., Schillings, C., Lohmann, S., Schroedter-Homscheidt, M., Buell, R., Trieb, F., 2004. Solar energy mining: a high-quality satellite-based service to provide direct solar radiation for Europe, Brazil, Africa and Asia. In: Proceedings of the SolarPACES International Symposium, Oaxaca, Mexico.

Michalsky, J.J., Perez, R., Seals, R., Ineichen, P., 1994. Degradation of solar concentrator performance in the aftermath of Mount Pinatubo. Solar Energy 52 (2), 205-213.

Molineaux, B., Ineichen, P., 1996. Impact of Pinatubo aerosols on the seasonal trends of global, direct and diffuse irradiance in two northern mid-latitude sites. Solar Energy 58 (1-3), 91101.

NCAR, 2004. Available from: <http://dss.ucar.edu/pub/reanalysis/FAQ.html>.

Pinker, R.T., Zhang, B., Dutton, E.G., 2005. Do satellites detect trends in surface solar radiation? Science 308, 850-854.

Press, W.H., Teukolsky, S.A., Vetterling, W.T., Flannery, B.P., 1992. Numerical Recipes in C. Cambridge University Press, 1020 pages.

Robock, A., 2000. Volcanic eruptions and climate. Rev. Geophys. 38 (2), 191-219.

Rossow, W.B., Desormeaux, Y., Brest, C.L., Walker, A., 1992. International Satellite Cloud Climatology. Project (ISCCP) radiance calibration report. WMO/TD 520, World Climate Research Programme (ICSU and WMO), $104 \mathrm{pp.}$

Rossow, W.B., Walker, A.W., Beuschel, D., Roiter, M., 1996. International Satellite Cloud Climatology Project (ISCCP) description of new cloud datasets. WMO/TD 737, World Climate Research Programme (ICSU and WMO), 115 pp.

Rossow, W.B., Schiffer, R.A., 1999. Advances in understanding clouds from ISCCP. Bull. Amer. Meteor. Soc. 80 (11), 22612287.

Sato, M., Hansen, J.E., McCormick, M.P., Pollack, J.B., 1993. Stratospheric aerosol optical depths, 1850-1990. J. Geophys. Res. 98 (D12), 22987-22994.

Schiffer, R.A., Rossow, W.B., 1983. The International Satellite Cloud Climatology Project (ISCCP): the first project of the World Climate Research Programme. Bull. Amer. Meteor. Soc. 64 (7), 779-784.

Schillings, C., Mannstein, H., Meyer, R., 2004a. Operational method for deriving high resolution direct normal irradiance from satellite data. Solar Energy 76, 475-484.

Schillings, C., Meyer, M., Mannstein, H., 2004b. Validation of a method for deriving high resolution direct normal irradiance from satellite data and application for the Arabian Peninsula. Solar Energy 76, 485-497.

Simmons, A.J., Gibson, J.K. (Eds.) 2000. The ERA-40 Project Plan. ERA-40 Project Report Series No. 1, ECMWF, Reading, UK, $62 \mathrm{pp}$.

Tegen, I., Hollrig, P., Chin, M., Fung, I., Jacob, D., Penner, J., 1997. Contribution of different aerosol species to the global aerosol extinction optical thickness: Estimates from model results. J. Geophys. Res. 102 (D20), 23895-23915.

Wild, M., Gilgen, H., Roesch, A., Ohmura, A., Long, C.N., Dutton, E.G., Forgan, B., Kallis, A., Russak, V., Tsvetkov, A., 2005. From dimming to brightening: decadal changes in solar radiation at Earth's surface. Science. 308, 845850 . 
Yang, P., Gao, B.-C., Baum, B.A., Yong, X.H., Wiscombe, W.J., Tsay, S.-C., Winker, D.M., Nasiri, S.L., 2000. Parameterization of the scattering and absorption properties of individual ice crystals. J. Geophys. Res. 105 (D4), 4699-4718.

Yang, S.-K., Hou, Y.-T., Miller, A.J., Campana, K.A., 1999. Evaluation of the Earth radiation budget in NCEP-NCAR reanalysis with ERBE. J. Clim. 12 (2), 477-493.
Zhang, Y.-C., Rossow, W.B., Lacis, A.A., Oinas, V., Mishchenko, M.I., 2004. Calculation of radiative flux profiles from the surface to top of atmosphere based on ISCCP and other global datasets: Refinements of the radiative transfer model and the input data. J. Geophys. Res. 109 (D19), D19105. 